\title{
Indus Ceramic Industries: Complexities, Challenges and Prospects*
}

\author{
K Krishnan**
}

(Received 20 June 2018)

\begin{abstract}
The study of ceramic industries of the Indus Valley Period has largely been descriptive, involving their use as a chronological marker and a determining tool to understand the extent of cultural boundaries. However, with the introduction of new methodologies and analytical techniques, primarily borrowed from material sciences, an increased emphasis has been placed to assess the quality of ceramics and its links to various processes involved in their manufacture. These studies have given us an overall idea about certain clay paste recipes, tentative provenance of the raw-materials, composition of slips and decorative pigments, baking conditions and temperatures, and probable architecture of pottery kilns. From an overall review of ceramic studies, we now know that there are simple as well as complex ceramic manufacturing methods adopted by the Indus Valley ceramic manufacturers. However, to have an overall understanding of its various technological dimensions, several intangible components of the society needs to be understood. These include the organizational aspects of ceramic production, transportation mechanism that led to the movement of ceramics from the place of its manufacture to other destinations, the dissemination of technological knowhow between different settlements and regions. Moreover, we still have not understood whether the spread of specific ceramic types within the larger and adjacent domains of the Indus Civilization, occurred as a result of trade of goods where ceramics acted as containers for specific materials; for instance, liquids or special ceramics themselves being transported to other places as trade commodities. Further, we still have not reached a stage where we could work out the nature of polity and other social mechanisms that supported this trade/ exchange activities. The paper in this regard reviews the researches undertaken in the realm of ceramic industries of the Indus Valley Civilization and identify the unexplored areas of Indus ceramic industries.
\end{abstract}

Key words: Ceramics, Cottage and Industrial Production, Indus Valley Civilization, Part-time and full-time occupation, Specialization, Specialist Potters, Standardization.

\section{INTRODUCTION}

Much has been written on the Indus Valley ceramics and a great majority of these writings have emphasised that the Indus ceramic industries are advanced in its quality, typological variety and in the overall standardisation of techniques of production. These writings are primarily a description of visible attributes of ceramics, evolution of its forms, appearance and dis- appearance of different variety in various cultural phases within the Indus Valley period.

Despite the fact that a large number of scientific methods were employed in the analysis of a variety of ceramics from outside the Indus Valley complexes on its contemporary and later period ceramics, within South Asia (Hegde, 1962, 1975; Gogte, 1997) and outside of it (Peacock, 1969; Tite and Bimson, 1991), the Indus Valley

\footnotetext{
* Presented at History of Science Seminar, Technology During Harappan Period, organised by Professor Vasant Shinde on $15^{\text {th }}$ September 2017 at Indian National Science Academy, New Delhi.

**Department of Archaeology and Ancient History, The Maharaja Sayajirao University of Baroda, Vadodara - 390 002, Email: krishnan.msu@gmail.com
} 
ceramics received very less attention in terms of application of scientific techniques to assess its quality and other properties with a few exceptions (Vats,1974; Marshall, 1931; Rao, 1963). This paper assesses the researches undertaken in the realm of ceramic industries of the Indus Valley Civilization and identifies the less attempted areas of researches on Indus Valley ceramics.

A number of theories explain that the Indus Valley Civilization developed from regional Chalcolithic cultures; a phase often referred to as the regionalization era. During the second part of $4^{\text {th }}$ millennium $\mathrm{BCE}$ and the first part of third millennium BCE several such small village settlements existed within the core and adjacent regions of Indus Valley. These regional Chalcolithic settlements interacted among themselves shared goods and ideas for their subsistence, survival and general societal changes, but at the same time retained their identity. This was followed by an integration era, which is usually referred to as classical Harappan / mature Harappan, where one sees elements of continuity from the previous phase and also elements of assimilation and integration from the regional cultures. This integration era lasted for nearly 500 years. This was followed by a localization era, where several cultural elements seen during the integration era either disappeared or underwent transformation. Almost all artefacts representing the key traits of Indus Civilization either disappeared or underwent major changes during the localization era. This also led to several migrations and spread of population to new lands, where they defined different adaptation strategies. Thus, the story of Indus Valley Civilization is primarily a transformation from regionalization era to integration era and further to localization era (Shaffer and Lichtenstein, 1989).

\section{Ceramic Production}

Vessel form/ shape, texture, composition and an overall description form key components of ceramic studies. To understand these aforesaid parameters, it is necessary to have an overall idea about its manufacturing process which determines its properties or attributes that form the identity of a great majority of various cultural groups. There are several stages of production in ceramic manufacturing; (i) collection of clay, (ii) preparation of clay paste, (iii) forming of vessels, (iv) drying them to leather hard stage, (v) treating/ modifying the surface appearance by the application of slip and/ or decorating it and (vi) baking them. One of the most important steps in ceramic manufacturing is the collection of clay. Potters generally prefer to use a raw material, which is comfortable for them to use. They identify the right clay through a 'non-verbal feel'. This is proven through ethnoarchaeological study (Krishnan and Rao, 1994). The clay that is collected is refined either through sieving or levigation or elutriation depending on the nature of the raw material and quality of the product to be made. The forming of the vessel is done through a variety of methods; raising/ sinking thin clay slabs, using a mould, hand making, using coiling techniques or throwing them on a wheel (turn table, slow wheel, fast wheel, motor wheel). Vessels that are made at the first stage are smaller in size and if necessary they are enlarged with the help of a rounded anvil and dabber. The surface of the vessel is made even and smooth using thin bone or soft wood scrapers. These vessels are dried to a leather hard stage by keeping them under shade. The surface of the dried vessels is often coated with a thin clay paste known as 'slip' or 'wash'. Decorations such as incised lines, paintings, stamps, appliqués, glaze etc are executed over this. The vessels are then baked in a kiln (open or closed), either in an oxidising environment or in a reducing environment or in a combination of both the environments. The final step is distributing the ceramics to the users. A great majority of the aforesaid processes have been identified within the archaeological context. 


\section{Studies on the Indus Ceramic INDUSTRIES}

Amongst the artefacts of the Indus Valley Civilization, ceramics have received a lot of attention from researchers due to its ubiquitous presence in large quantities and its varieties. Further, it is interesting to note that such a vast variety of good quality pottery is present in almost all settlements within a culturally definable area that encompasses more than 1.4 million sq. $\mathrm{Km}$. A great majority of studies have been done on these ceramics, which is mainly typological in nature and forms as a major part of any excavation report. There are also studies that are either focussed on typology (Manchanda, 1972; Dales and Kenoyer, 1986) or decorative motives (Starr, 1941; Dales and Kenoyer, 1986) present on the ceramics. The earlier attempts to carry out wet chemical analysis on Indus Valley ceramics were done by Sana Ullah (Vats, 1974), Hamid (Marshal, 1931) and by Lal (Rao, 1963, 1979, 1985). Similarly microscopic methods were first used by Plenderleith (Marshal,1931). Several attempts were made from 1980s onwards to characterize the Indus Valley ceramics based on its composition (Krishnan, 1982, 1986, 1992; Krishnan and Hedge, 1986-87; Krishnan et.al., 2005) by using a variety of methods. Further, there are attempts to draw cultural information from the scientific data (Herman and Krishnan, 1994; Bhagat, 2001; Krishnan and Shah, 2005; Vinod, 2010; Patel, 2017) followed by explaining levels of specialization (Krishnan et.al., 2005). Although a lot of work has been done, successful correlations between cultural data and scientific data was not tried due to the paucity of required information as the analysts and archaeologists mostly worked in isolation. Within this context, an attempt is made here to address issues pertaining to standardization and specialization. The overall organizational aspects of the ancient ceramic industries are not emphasized much, as it incorporates several cultural intangible that are not easily deducible.

\section{Standardization and Specialization of Indus CERAMIC INDUSTRIES}

To begin with, it may be proposed that specialization is a result of full time occupation and is present in semi and fully administered society. Further, a specialist potter could exist only in fully administered societies. These propositions are verified here with the help of a few case studies. The methods of analyses employed for these studies are thin-section analysis on representative ceramic samples, $\mathrm{x}$-ray diffraction analysis, scanning electron microscopy with EDAX attachment on it. Using the results of these analyses from sites; Nageswar and Vagad in Gujarat and Bhirrana in Haryana, it was observed that the clay provenance was more or less within the proximity of these sites (Krishnan, 1986; Krishnan and Hegde, 1986-87; Krishnan et.al., 2012). The archaeological evidence in the form of vitrified sherds, which are indicators of pottery production also support this view.

Reviewing the paste texture of ceramics is one of the ways of understanding clay paste preparation techniques, which is an important component that supports the function of vessels. Clay needs to have non-plastic inclusion within it for reducing its plasticity and enhancing its workability. The non-plastic inclusions make it porous enough so that while drying and heating the various forms of water, which is present in the clay; hygroscopic, absorbed and lattice water easily escape without breaking the vessel. Also there is a tradition of adding organic materials to the clay paste while preparing it, which burn away while baking leaving the pores. It may be noted that a great majority of the clay deposits do contain sand/ rock particles, often referred to as mineral phases and other inclusions which are non-mineral phases. The non-mineral phases are primarily organic materials; either shells or fibres or grog, which is essentially a smaller and finer fraction of a crushed pot-sherds. Therefore, in certain clays the potter does not need to add sand. But if the 
quantity of sand or other inclusions are very high and/ or if the particle sizes are very large they are removed using a sieve. The presence of these nonplastic inclusions at an optimum level enhances the quality of the clay.

Most of the Indus Valley ceramics whose thin-sections have been studied do contain nonplastic inclusions whose sizes go up to $1000 \mu$. This is the largest fraction of coarse sand. Interestingly, when one calculates the grain-matrix ratio of the Indus Valley ceramics, it falls either as $1: 2$ or $1: 3$. The consistency in such a grainmatrix ratio is significant as it is a reflection of the potters' knowledge of the raw material and his/ her ability to maintain homogeneity in paste texture while preparing the clay paste. Most of the clay deposits do have sand particles whose size fluctuation is greater and fairly inconsistent in terms of their grain-size distribution character. Further, almost all clay deposits contain grains of varying shape; angular, sub-angular, sub-rounded and rounded. This grain-shape is dependent on the nature of the deposit; primary or secondary and also the distance to which the raw material has been transported. The raw material treatment is of utmost importance as it determines the quality of the product. Those clay deposits that contain higher amount of sand are treated in such a way that the excess sand is removed to maintain the optimum quantity. If it does not have sufficient quantity of sand, it requires addition of the sand. Ethoarchaeological investigations followed by experimental studies have revealed that if clay is mixed homogenously the grain-size distribution pattern that emerges is of unimodal nature and if sand is added, it gives rise to bimodal distribution pattern (Krishnan and Rao, 1994). However, while carrying out petrographic analysis of ceramic thinsections followed by point counting it has also been noticed that there are instances of semibimodal or semi-unimodal nature of grain-size distribution character. An explanation to this has not yet been given.
It may be noted that one of the major failures in ranking the clay paste preparation techniques is the limited work undertaken in this area. In addition, the lack of thin-section analysis of ceramics at major settlements which give a longer chronology of a single culture hinders our understanding of clay paste preparation techniques that were adopted. Such studies if conducted will reveal the developmental stages of paste preparation techniques. Similarly if ceramics from multicultural period sites are studied, it would reveal the variations in ceramic paste, which is in turn a reflection of the cultural tradition. It is also observed that vessels that are frequently heated, especially cooking vessels do contain minerals, such as, feldspar, augite and calcite, whose coefficient of expansion is very close to that of clay (Rye, 1976). This prevents it from undergoing thermal shock, which would further lead to breakage and shrinkage. These mineral assemblages are found in the ceramics from Indus Valley Period within Gujarat. As these minerals are commonly found in the sediments of Gujarat, it is not appropriate to state that the potters prepared the clay paste by adding specific nonplastic inclusions based on the function of the vessels. Typological studies of cooking vessels within the Indus Valley Period sites in Gujarat and the core Indus regions have revealed a resemblance in its overall form. The mineralogy of the non-plastic inclusions present in ceramics from various sites also show a resemblance, which suggest that the clay paste preparation techniques of the classical Indus Period had been very specialized especially while making the cooking vessels. This makes one further propose that there may have been common workshops for production of cooking vessels. However, more samples from multiple sites need to be studied before one arrives at any conclusions.

There are many vessel forming techniques that have been suggested by researchers to explain the forming methods of the Indus Ceramics. These 
include shaping the vessels with hand, mould, coiling and on wheel (slow and fast). These conclusions have been arrived at by studying the vessel morphology; nature of undulations on the surface and also the striation marks. Such conclusions are not necessarily valid as it is primarily based on the observations of the external attributes. Ethnographic surveys have revealed that in general most of the pottery, except the smaller vessels and dishes, are made through multiple techniques or in parts which are joined afterwards. This requires special skill and an imaginative mind for the potter. Standardization of ceramics during the Indus phase is another aspect that has been peripherally explored by ceramic specialists. These have been done through metric analyses; by measuring the rim diameter of a specific category of vessel; to cite an example, bowl, to see how far it fluctuates within specific contexts in a period (Vinod and Krishnan, 2011). Minor fluctuations are usually ignored as they are a result of either different potters' hand or within and/ or workshops. Similarly by assessing thickness of the rim of vessels, elements of standardisation are worked out. Much work has also been done with regard to the study of paintings on the ceramics (Starr, 1941; Choksi, 1994). These include comparing and contrasting designs, its pattern and symmetry of its arrangements on the vessels. These indicate the aesthetic sense of the potters and the society that use it.

Propositions have also been worked out on the origins of ceramic technology, its diffusion and spreads. Further attempts are also made to see if specialized potting or specialist potters did exist. Specialized potting refers to the production of specific forms that requires a different skill, to cite one example, manufacturing of large storage jars. Experimental Archaeological studies have proven that these are made in parts, either on wheel or using coiling technique and finally joined. These are made in parts as the production of such vessels in one piece is not possible because of their size. Therefore, these have to be made in parts and joined, which can only be done by trained potters.

The idea of specialist potter emerges from the attempt to understand the production of exclusive types, to cite an example the production of the 'sintered' Reserved Slip Ware (Fig. 1). The terms 'Reserved Slip' refer to a special surface treatment where two slips are initially applied on the vessel surface, followed by selective removal of the upper one with a comb-like soft instrument to partially expose the lower slip, so that a colour contrast is visible. The antiquity of the technique of presenting the slips with such colour contrast goes back to the early Harappan cultures, but the 'sintering' effect is visible only in the Harappan phase. The glossy appearance on its surface is due to sintering. While examining its chemical composition along with other Harappan ceramics, it was found that the dominant element in the black pigment is iron, both in black on Red and Reserved Slip Wares. The red slip of the black-on-red ware variety also had iron in it. This was causing complexities in explaining the phenomena of obtaining black and red colour on the surface of black-on-red wares and black and grey on the Reserved Slip Ware. Scanning electron microscopic analysis of the ceramic cross section followed by EDAX analysis gave an idea of the microstructure and composition. It was found that the black painted surface of the ceramic had a sintered surface. Compositional analysis indicated

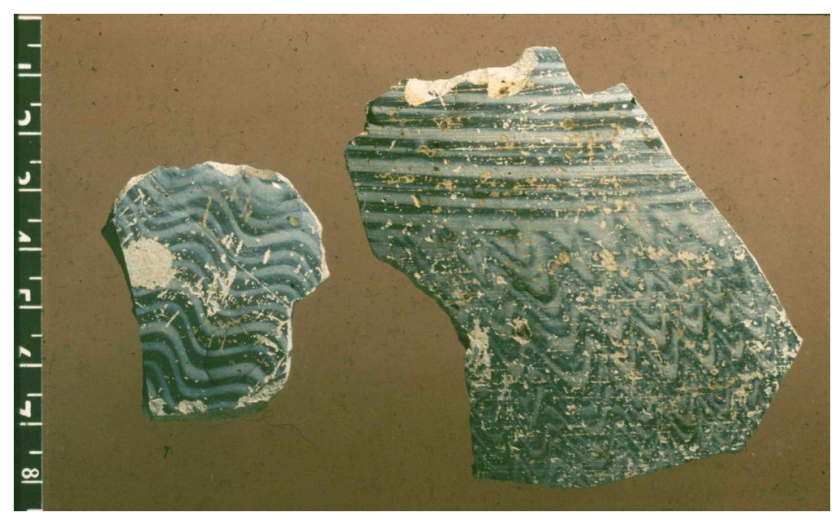

Fig. 1. 'Sintered' Reserved Slip Ware Sherds 
that clay with which the black colourant (Iron oxide) was mixed was extremely very fine. The pots may have been heated in a kiln, which may have had a vertical up-draught system. This vertical up-draught system can be created in any kiln which is sealed from all sides with clay before starting the baking process. Thus, when the burning/ baking activity within the up-draught kiln (oxidising environment) reaches the maximum temperature, the potters close the vents to complete the baking and put the fire off. At this time also, burning activity continues within the kiln, but in inadequate supply of or absence of oxygen (reducing environment). When the cooling cycle begins, the vents are opened to allow surrounding air to get in, which again creates an oxidising environment. Experimental archaeological studies were conducted to recreate the Harappan quality vessels. These were not entirely successful, as the author and the potters may have certainly missed certain technical steps in the Harappan ceramic technology, but was able to reproduce vessels, though a little inferior in quality. During the experiment, it was noticed that the whole pots were red in colour at the top temperature. They turned mostly dark when the vents were closed and the whole pot except the pigmented area turned red while the vents were opened for cooling. Thus, it appears that one of the methods with which the Indus Ceramics were baked was in an oxidisingreducing-re-oxidising cycle (Krishnan, 1992). In case of Reserved Slip ware the same method of baking must have been adopted. The presence of mullite in the ceramic body of the Reserved Slip ware suggest that these ceramics were heated to over $1000^{\circ} \mathrm{C}$ and also from the few samples analysed the black colour of the Reserved Slip Ware was due to the presence of hercynite (Fe $\mathrm{Al}_{2} \mathrm{O}_{4}$ ) (Krishnan et.al. 2005).

\section{Discussion}

While looking at the overall results of the studies on Indus Valley ceramics, it appears that during the Indus Valley Period a wide variety of techniques were employed for the manufacturing of ceramics. For urban potters potting would have been a full time occupation during the Indus Valley Period. Such full time occupations do require support from the state, its polity and its other policies. Full time occupations are mostly a reflection of specialization in ceramic industries. The general agreement in the quality of ceramics seen from various Indus Valley settlements suggests that a system of imparting technological and scientific knowledge existed within the Indus society. This would have led to an overall agreement in the material culture in terms of its appearance and composition.

The technology of the Reserved Slip ware; its fabrication process, firing conditions, controlled way of preparing the clayey slips etc. suggest that only specialist potters could have achieved this stage. This is further supported by its restricted distribution within the settlement and within the overall cultural geography of the Indus Valley Civilization.

Studies on Indus ceramics have so far revealed that they were the product of a fairly to highly specialized industry. More studies need to be done to fully understand the organization aspect of the ceramic industries of the Indus Valley Period. It may also be noted that products of cottage ceramic industries also existed within the Indus Ceramics repertoire. The Micaceous Red Ware (Fig.2) found in and around the Gulf of Cambay may be cited as an example of it. Its surface has undulations and its slip treatment is different as it is relatively thicker in comparison to the classical Indus ceramics. The undulatory surface suggests that it is probably made using a mould or a slow wheel. The execution of paintings on it is different from that of the Indus types as it is a little irregular and unsteady. So far, we have not been able to identify a separate cultural phase characterized by Micaceous Red Ware. But, it is almost certain that the origin of its technique of production goes to a non-Harappan phase. Within 


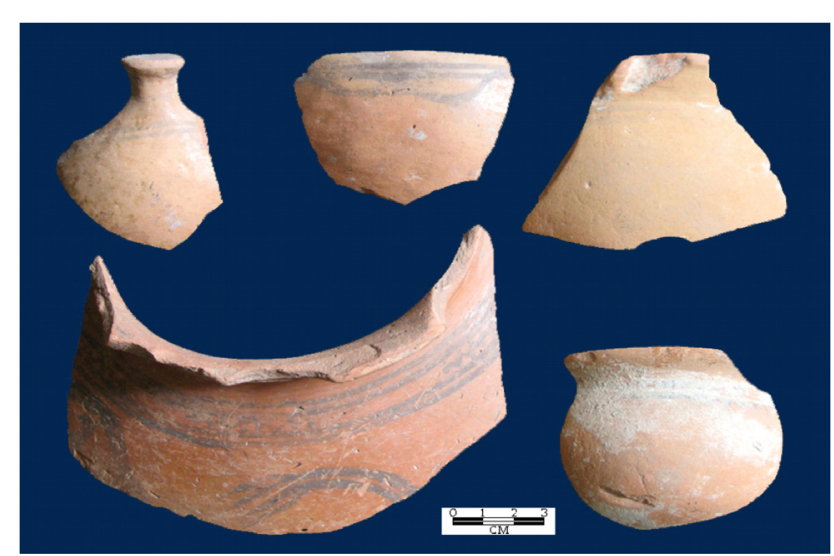

Fig. 2. Micaceous Red Ware Sherds

this context it is possible to state that both cottage and industrial production of ceramics co-existed during the Indus valley phase. This further suggests the existence of a complex cultural environment within the wider domain of craft activities during the Indus Valley Period.

\section{BIBLIOGRAPHY}

Bhagat, S. A Study of the Harappan Pottery Tradition in Saurashtra (with Special Reference to Padri and Tarsara, Bhavnagar District, Gujarat) (Unpublished Ph.D. Thesis), Department of Archaeology, Deccan College Post-Graduate and Research Institute, Pune, 2001

Choksi, A. Ethnoarchaeological Study of Pottery Manufacture in Kutch. (Unpublished Ph.D Thesis), Department of Archaeology and Ancient History, The Maharaja Sayajirao University of Baroda, Vadodara, 1994

Dales, G F and Kenoyer, J M. Excavations at Mohenjodaro, Pakistan: the Pottery, The University Museum Monograph, No. 53, The University Museum, University of Pennsylvania, Philadelphia, 1986.

Gogte, V D. The Chandraketugahr-Tamluk region of Bengal: Source of the Early Historic Rouletted ware from India and Southeast Asia, Man and Environment, 22.1 (1997): 69-85.

Hegde, K T M. Technical Studies in Northern Black Polished (N.B.P.) Ware, Journal of the M. S. University of Baroda 11.1 (1962): 159-161.

Hegde, K T M. The Painted Grey Ware of India, Antiquity, 49(1975):187-190.
Herman, C F and Krishnan, K. Micaceous Red Ware: A Gujarat Proto-Historic Cultural Complex or just Ceramic? In A. Parpola and P. Koskikallio (Eds.), South Asian Archaeology 1993, Vol I. Annales Academic Scientiarum Fennicae Helsinki Series B, Vol 271(1994):225-43.

Krishnan, K. Identification and Determination of the Composition of the Pigments used in the Decoration of Chalcolithic Period Pottery in Gujarat (Unpublished M.A. Dissertation), Department of Archaeology and Ancient History, The Maharaja Sayajirao University of Baroda, Vadodara,1982

Krishnan, K. Chemical and Petrological Studies in Ancient Indian Pottery (Unpublished Ph.D Thesis), Department of Archaeology and Ancient History, The Maharaja Sayajirao University of Baroda, Vadodara,1986

Krishnan, K. An Analysis of Decorative Pigments and Slips on Harappan Pottery from Gujarat, South Asian Studies 8(1992):125-132.

Krishnan, K and Hegde, K T M. Chemical and Petrographic Studies in Pottery of Harappa Culture in Gujarat, Journal of the M. S. University of Baroda, 1986-87 (Humanities) 35-36.1 (1986-87): 27-56.

Krishnan, K and Rao, V. A Study of Clay Paste Preparation by Potters through Grain Size Analysis, South Asian Studies 10(1994): 113-117.

Krishnan, K and Shah, K. Beyond Wares and Shapes: Gaining a Petrographic Perspective on Ancient Indian Pottery. In Biswas, A K (ed.). Sciences in Archaeology and Archaeomaterials, D. K. Printworld, New Delhi, 2005, pp. 135-156.

Krishnan, K; Freestone, I C and Middleton, A C. The Technology of 'Glazed' Reserved Slip Ware - A Fine Ceramic of the Harappan Period, Archaeometry, 47.4 (2005): 691-703.

Krishnan, K; Rao, L S; Vinod, V; Smitha S; Kumar, Prabhin Sukumaran and Kushwaha, Dilip Kumar. Petrography of Ceramics from Bhiranna: A Preliminary Study. Man and Environment 37.2 (2012): 18-27.

Manchanda, O. A Study of Harappan Pottery, Oriental Publishers, Delhi, 1972

Marshall, J. (ed.) Mohenjo-Daro and the Indus Civilization, Arthur Probsthain, London, 1931

Patel, S P. Dynamics of Ceramic Technological Style and Boundaries of the Sorath Harappans (Unpublished Ph.D Thesis), Department of Anthropology, New York University, New York, 2017 
Peacock, D P S. Neolithic Pottery Production in Cornwall, Antiquity 43(1969):145-149

Rao, S R. Excavation at Rangpur and Other Explorations in Gujarat, Ancient India (Bulletin of the Archaeological Survey of India) 18 \& 19 (1962-63): 1207.

Rao, S R. Lothal: A Harappan Port Town, 1955-62, Memoirs of the Archaeological Survey of India, No. 78. Vol. 1, Archaeological Survey of India, New Delhi, 1979.

Rao, S R. Lothal: A Harappan Port Town, 1955-62. Memoirs of Archaeological Survey of India, No. 78.Vol. 2, Archaeological Survey of India, New Delhi, 1985

Rye, O S. Keeping Your Temper under Control: Materials and the Manufacture of Papuan Pottery, Archaeology and Physical Anthropology in Oceania 19.2 (1976.): 205-11.

Shaffer, J G and Lichtenstein, D A. Ethnicity and Change in the Indus Valley Cultural Tradition, In J. M. Kenoyer (ed.). Old Problems and New Perspectives in the
Archaeology of South Asia, Wisconsin Archaeological Reports, 2, Wisconsin Archaeological Reports, Madison, 1989, pp.117-126

Starr, R F S. Indus Valley Painted Pottery, Princeton University Press, Princeton, 1941.

Tite, M S and Bimson, M. A Technological Study of English Procelain, Archaeometry, 33.1 (1991): 3-27.

Vats, M S. Excavation at Harappa (First published in 1940), Government of India, Delhi; Bhartiya Publishing House, Varanasi, 1974

Vinod, V. Specialization in Harappan Pottery production: A Case Study from Gujarat. (Unpublished Ph.D. Thesis), Department of Archaeology and Ancient History, The Maharaja Sayajira University of Baroda, Vadodara, 2010

Vinod, V and Krishnan, K. Potting Skills: An Ethnographic Perspective, Man and Environment, 36.1(2011): 8891. 